\title{
New structural and spectroscopic data for eosphorite
}

\author{
M. A. Hoyos and T. Calderon \\ Dept. Quimica-Agricola-Geologia y Geoquìmica Univ. Autònoma de Madrid, Cantoblanco, Spain \\ I. Vergara and J. Garcia-Solé \\ Dept. Fisica de Materiales, C-IV, Univ. Autònoma de Madrid, Cantoblanco, Spain
}

\begin{abstract}
X-ray diffraction refinement of the crystal structure of eosphorite has been carried out with reference to the orthorhombic space group Cmca. The structure is similar to that previously described by Hanson (1960), but the standard deviations are improved. Optical absorption and photoluminescence have also been studied for this mineral. Two sharp emission lines, denoted as $R_{1}$ and $R_{2}$, superimposed to a broad band $(630-750 \mathrm{~nm})$ have been related to the presence of $\mathrm{Cr}^{3+}$ ions. The excitation spectrum of these emissions confirms that the absorption (excitation) bands centred at $431 \mathrm{~nm}$ and 585 are related to with ${ }^{4} \mathrm{~A}_{2} \rightarrow{ }^{4} \mathrm{~T}_{1}$ and ${ }^{4} \mathrm{~A}_{2} \rightarrow{ }^{4} \mathrm{~T}_{2}$ spin allowed transitions of this ion.
\end{abstract}

KEYWORDS: eosphorite, crystal structure, luminescence optical absorption.

\section{Introduction}

EOSPHORITE is the maganese-rich end-member of the childrenite-eosphorite series, $(\mathrm{Fe}, \mathrm{Mn}) \mathrm{Al}$ $\mathrm{PO}_{4}(\mathrm{OH})_{2} \cdot 2 \mathrm{H}_{2} \mathrm{O}$, formed by hydrothermal phosphatisation of metasediments and associated with the intrusion of granites (Braithwaite and Cooper, 1982).

Crystals are most commonly of a bipyramidal habit with striated faces elongated parallel to the $c$ crystallographic axis. Members of this diadochic series can exhibit a great variability of colours and hues (e.g. colourless, pale brown, reddish brown, yellowish brown, pale cream, etc.). These colours are probably related to different $\mathrm{Fe}^{2+} / \mathrm{Mn}^{2+}$ and $\mathrm{Fe}^{2+} / \mathrm{Fe}^{3+}$ ion ratios.

First studies on the crystal structure of childrenite were carried out by Barnes (1949), Hurlbut, (1950), and Barnes and Shore (1951), respectively. However, their data were not conclusives with respect to the assignment of the space group symmetry (Bba2 or Bbam; i.e. orthorhombic or pseudo-orthorhombic symmetry). Later, Hanson (1960) proposed an 'approximate' eosphorite structure, belonging to the pseudo-orthorhombic spacial group of symmetry Bbam. However the high value calculated by Hanson (1960) for the residual factor $R=0.16\left[R=\left(\mathrm{F}_{\mathrm{o}}-\mathrm{F}_{\mathrm{c}}\right) / \mathrm{F}_{\mathrm{o}}\right]$ indicates that, in spite of the correct structure, some refinement has become necessary.

In this paper an X-ray diffraction refinement for the crystal structure of eosphorite is described. In addition, new data regarding the optical properties of this mineral are presented. These data throw light on the nature of some absorption and emission bands of this mineral.

\section{Experimental}

The orange prismatic crystals of eosphorite, from Taquaral (Brazil), used in this work were bought from a dealer. In this specimen of eosphorite the $\mathrm{Mn}: \mathrm{Fe}$ ratio is about $4: 1$ (Table 1).

The crystal selected for data collection was ground to a sphere of $0,3 \mathrm{~mm}$ diameter. Intensity data were collected on an automatic four-circle Enraf-Nonius CAD-4 diffractometer, using graphite-monochromated Mo- $K \alpha$ radiation. Data were corrected for Lorentz and polarisation effects. An absorption correction, incorporated into the XRAY-76 system, was used (Stewart et al., 1976) for all computations.

Piezoelectric tests were carried out in a Hewlett Packard (LF 4260) impedance analyser using the 


\begin{tabular}{lcccc} 
Table 1 & & & & \\
& 1 & 2 & 3 & 4 \\
\hline Fe (total) & 24.30 & - & 7.6 & 5.40 \\
Mn & - & 23.99 & 13.4 & 19.45 \\
Al & 11.73 & 11.78 & 10.9 & 10.18 \\
P & 13.48 & 13.53 & 13.30 & 14.15 \\
Ca & - & - & 1.74 & 0.73 \\
Mg & - & - & 0.6 & 0.36 \\
Si & - & - & - & - \\
Na & - & - & - & - \\
Cr & $C h$ & Eo & $\mathrm{Ch}_{36} \mathrm{EO}_{64}$ & $\mathrm{Ch}_{24} \mathrm{EO}_{76}$ \\
Formula & & & - &
\end{tabular}

1. Childrenite theoretical.

2. Eosphorite theoretical.

3. Eosphorite, Taquaral, Brazil (Braithwaite, 1982).

4. Sample used in this work.

Analysis of childrenites and eosphorites, wt. Characterization of the chemical composition of our eosphorite was carried out by means of A.A. (Atomic absorption spectrometry, Perkin Elmer, 503). using induced coupling plasma (ICP)

resonance frequency method. Optical studies were made in a polarising microscope using cosphorite prismatic sections.

Table 1 shows details of the chemical analysis of our eosphorite crystal, compared with other eosphorite-childrenite crystals.

Unpolarised optical absorption measurements were performed in a CARY-2400 spectrophotometer. Samples of $6 \times 4 \times 2 \mathrm{~mm}^{3}$ were cut perpendicularly to the $c$ crystallographic axis and all faces were polished. Then the electric field of the light was perpendicular to the $c$-axis in all the spectra.

Photoluminescence (excitation-emission) spectra were measured in a Jobin Ivon, JY-3CS, spectrofluorimeter, with a resolution of $1 \mathrm{~nm}$ in emission.

\section{Results and discussion}

$X$-Ray diffraction results. The crystal data, experimental data, solution and refinement of structure, are shown in Table 2.

The structure was solved by the Patterson method, using successive Fourier syntheses, including the $\mathrm{H}$ atoms. The structure was refined using first an isotropic thermal parameter, and then an anisotropic parameter, for the non- hydrogen atoms.* The $\mathrm{H}$ atoms were included in a mixed refinement with the isotropic thermal fixed parameter. The $\mathrm{Mn} / \mathrm{Fe}$ population factor was considered to be the expected from the chemical analysis. Finally, the $R$ values obtained were $R=0.041$ and $R_{\mathrm{w}}=0.054$.

The scattering factors were corrected for anomalous dispersion using the values given in the International Tables for X-Ray Crystallography (1974).

The final Fourier synthesis difference was on peaks of $0.5 \mathrm{e} / \mathrm{A}^{3}$. The calculated atomic positions are listed in Table 3. Heavy atoms that do not present standard deviations in Table 3 were considered to be fixed in the refinement, because they present special positions in the structure. No refinement was used for $\mathrm{H}$ atoms in the structure. It is considered that the agreement is quite good and then the described structure must be considered as correct.

The crystal structure is described with reference to the orthorhombic space group $\mathrm{Cmca}$ with $a=6.928(1), b=10 \cdot 445(1), c=13 \cdot 501(2) \AA$. The Cmca space group is the correct group while the 'Bdam' one calculated by Hanson (1960) is not recognised in the International Tables (and should be $\mathrm{Bbcm}=\mathrm{Cmca}$ ). The doubts raised by

* The anisotropic thermal parameters will be made available directly from the authors. 
Table 2

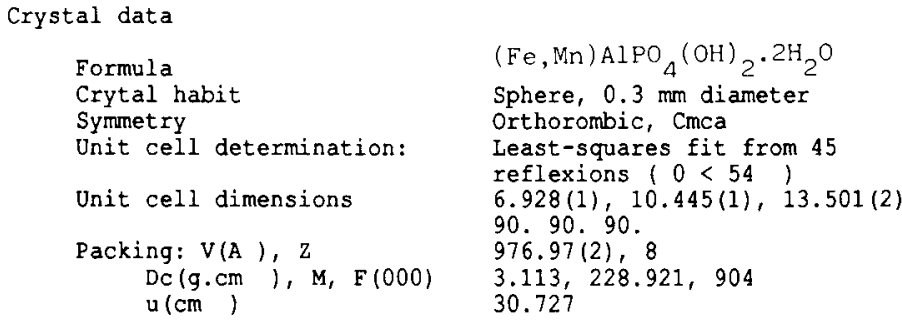

Experimental data

Technique

Number of reflexions : Measured Independent Observed

Range of hkl

Standard reflexions :

Max-min transmission factors :

Solution and refinement

Solution
Refinement
H atoms
Final F peaks
Final R and Rw
Computer and programs
Scattering factors
Anomalous dispersion

Four circle diffractometer: Nonius CAD4. Graphite oriented monochromator: $k-\propto$ Mo, w/20 scans, up Omax. 60.

$1 \mathrm{~min} . /$ reflex.

5323

4976 (I > 20(I) criterion)

$018,028,034,(\sin 0 /) \mathrm{mx} .1 .54$

2 reflexiones every 90 minutes

Variation : No

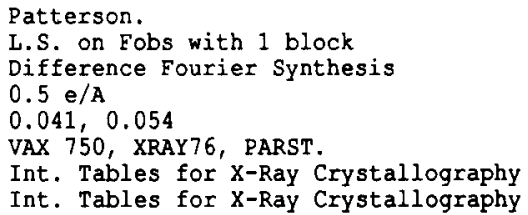

Crystal data, experimental data, solution and refinement for the eosphorite crystal

\begin{tabular}{|c|c|c|c|c|}
\hline АTOM & $\begin{array}{c}\text { Number in } \\
\text { cell }\end{array}$ & $x$ & $y$ & 2 \\
\hline$(\mathrm{Mn}, \mathrm{Fe})$ & 8 & 0.2500 & 0.1333 & 0.2500 \\
\hline$P$ & 8 & 0.0000 & 0.3772 & 0.3334 \\
\hline Al & 8 & 0.2500 & 0.2500 & 0,0000 \\
\hline $\mathrm{O}_{2}(\mathrm{O})$ & 8 & 0.0000 & $0.2656(1)$ & $0.2584(2)$ \\
\hline$O_{2}(0)$ & 8 & 0.0000 & $0.0067(x)$ & $0.2195(1)$ \\
\hline $\mathrm{O}_{3}\left(\mathrm{H}_{2} \mathrm{O}\right)$ & 8 & 0.0000 & $0,2522(1)$ & $0.0492(1)$ \\
\hline $0 .((\mathrm{OH}))$ & 16 & 0.1801 (2) & $0,1104(1)$ & $0,4093<0$ \\
\hline$O_{5}\left(0^{x}\right)$ & 16 & $0.3195,1$, & $0.1324(2)$ & $0.6006(0)$ \\
\hline $\mathrm{H}_{2}\left(\mathrm{H}_{2} \mathrm{O}\right)$ & 16 & 0.110 & 0.285 & 0.080 \\
\hline $\mathrm{H}_{0}\left(\mathrm{OH}^{-}\right)$ & 16 & 0.182 & 0.035 & 0.421 \\
\hline
\end{tabular}

Hanson (1960) about the crystal system and space group symmetry for eosphorite were resolved by taking into account the intensities of the $h k l$ and $\bar{h} k l$ reflections and the study of systematic absences. No differences in intensity were detected in this case. Because of this fact it can be suggested that, at least, our crystal does not belong to a monoclinic space group. Moreover, the reflections giving: $h k l(h+k=$ even); $h 0 l(l=$ even) and $h k 0(h=$ even $)$, were observed. This fact indicates that the eosphorite can be unambiguously assigned to the Cmca symmetry group of the orthorhombic system.

To check the presence of a centre of symmetry and thus verifying whether or not the symmetry is lower than orthorhombic, additional experiments 
were performed. These included a piezoelectricity test and some crystals-optics studies with a polarising microscope. The piezoelectricity test did not show evidence of activitiy in the frequency range from 100 to $1000 \mathrm{KHz}$. Thus the presence of a centre of symmetry can be assumed, and the Cmca orthorhombic space group of symmetry determined by X-ray diffraction is confirmed.

In relation with the crystal-optics experiments, straight extinction was observed in all cases and thus, again, no evidence of monoclinic symmetry was found.

Consequently it is possible to conclude that the symmetry is not lower than orthorhombic. All data obtained for eosphorite crystals indicate that the Cmca space group determined by X-ray diffraction is correct.

The calculated structure is equivalent to that described by Hanson (1960), but the standard deviations are improved. Now the structure can be considered as a system of linked polyhedra assembled in the following way: $(\mathrm{Mn}, \mathrm{Fe}) \mathrm{O}_{4}(\mathrm{OH})_{2}$ octahedra share opposite $\mathrm{O}-\mathrm{O}$ edges to form a set of endless chains parallel to the $a$-axis; $\mathrm{AlO}_{2}(\mathrm{OH})_{2}\left(\mathrm{H}_{2} \mathrm{O}\right)$ share opposite $\mathrm{H}_{2} \mathrm{O}$ corners to form a parallel set of chains. The two types of chain alternate, sharing $\mathrm{OH}$ corners to form an infinite sheet. Adjacent sheets are held together by phosphorus cations in tetrahedral coordination with oxygen ions, forming a threedimensional network.

A section of this structure is shown in Fig. 1, and the appropriate atomic positions and interionic distances are given in Tables 3 and 4 respectively. It is evident that the $(\mathrm{Mn}, \mathrm{Fe})$ octahedra are somewhat distorted. The shared edge is considerably shorter than the others, suggesting a repulsion between neighbouring (Mn, $\mathrm{Fe}$ ) cations. The other polyhedra are closer to a regular one (Figs. $2 a$ and $b$ ).

All the cation-anion distances are in good agreement with those found for similar coordination polyedra in other $(\mathrm{Al}, \mathrm{Fe})$-phosphate compounds; King and Sengier-Roberts (1988).

The lengths of the hydrogen bonds, previously suggested by Hanson (1960), have been calculated according to the correct identification of the $\mathrm{OH}$ and $\mathrm{H}_{2} \mathrm{O}$ groups. Thus the distances obtained for the $\mathrm{O}_{3}-\mathrm{H}_{2}-\mathrm{O}_{5}$ hydrogen bonds show that the $\mathrm{O}_{3}-\mathrm{O}_{5}$ distance is shorter than the oxygenoxygen distances observed in the aluminium octahedron (Table 4), according to the expected effect of the $\mathrm{H}$ atoms on the $\mathrm{O}_{3}-\mathrm{O}_{5}$ oxygen atoms.

Optical properties. As previously mentioned

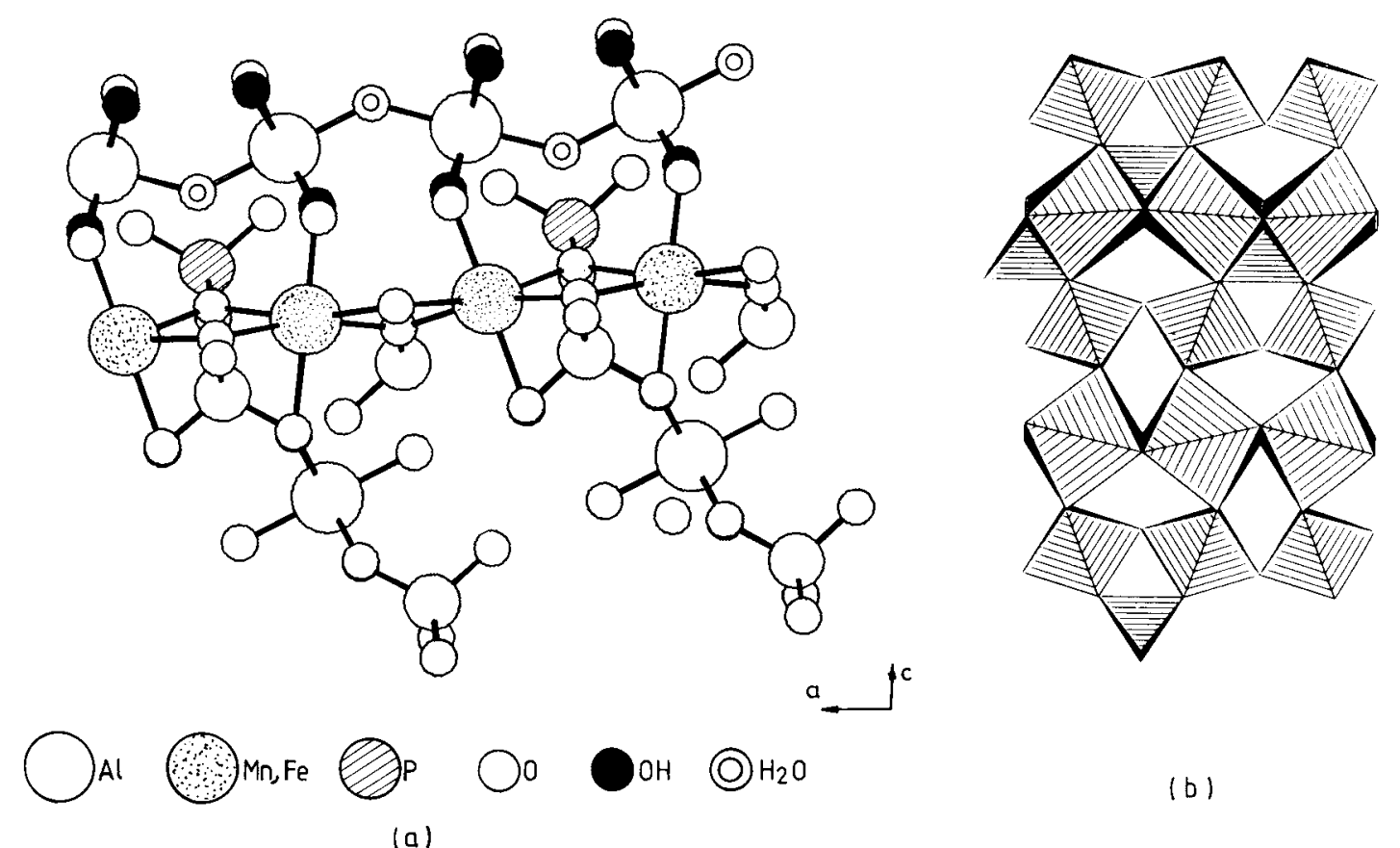

FiG. 1. (a) A section of the eosphorite structure showing the alternate chains of $\mathrm{Al}$ and $\mathrm{Mn}$ octahedra linked by $\mathrm{OH}$ groups. (b) Coordination polyhedra of the eosphorite structure. 
Table 4

\begin{tabular}{|c|c|c|c|}
\hline \multicolumn{2}{|c|}{$(\mathrm{Mn}, \mathrm{Fe}) \mathrm{O}_{4}(\mathrm{OH})_{2}$ octahedron } & \multicolumn{2}{|c|}{$\mathrm{AlO}_{2}(\mathrm{OH})_{2}\left(\mathrm{H} \mathrm{H}_{2} \mathrm{O}\right)$ z octahedron } \\
\hline$O_{1}-O_{2}$ &, $4714(s)$ & $0_{3}-0_{4}$ & $\begin{array}{l}2,6803 \text { (2) } \\
2,7239 \text { (3) }\end{array}$ \\
\hline $\mathrm{O}_{2}-\mathrm{O}_{2}$ & $.7547(3)$ & $\mathrm{O}_{3}-\mathrm{O}_{5}$ & $\begin{array}{l}2,6142(3) \\
2,6870(2)\end{array}$ \\
\hline$O_{1}-O_{a}$ & $\begin{array}{l}8871 \text { (2) } \\
, 5589 \text { (3) }\end{array}$ & $\mathrm{O}_{4}-\mathrm{O}_{5}$ & $\begin{array}{l}2,7670(4) \\
2,6898(3)\end{array}$ \\
\hline $\mathrm{O}_{2}-\mathrm{O}_{2}$ &, $5606(s)$ & & \\
\hline $\mathrm{O}_{2}=\mathrm{O}_{0}$ & $\begin{array}{l}.0181 \text { (3) } \\
.0490 \text { (3) }\end{array}$ & & \\
\hline$(\mathrm{Mn}, \mathrm{Fe})-\mathrm{O}_{1}$ & $2,2186(2)$ & $O_{3}-A 1$ & $1,8551(2)$ \\
\hline$(\mathrm{Mn}, \mathrm{Fe})-\mathrm{O}_{2}$ & $2,2176(2)$ & $0 .-\mathrm{Al}$ & $1,9647(2)$ \\
\hline$(\mathrm{Mn}, \mathrm{Fe})-\mathrm{O}_{4}$ & $2,2175(3)$ & $O_{3}-A I$ & $1,8935(2)$ \\
\hline \multicolumn{2}{|c|}{ PO. Tetrahedron } & \multicolumn{2}{|c|}{ Hydrogen bonds } \\
\hline$O_{1}-O_{2}$ & $2,5359(2)$ & $\mathrm{O}_{3}-\mathrm{O}_{3}$ & $2,6142(3)$ \\
\hline $\mathrm{O}_{2}-\mathrm{O}_{5}$ & $2,5145,2)$ & $\mathrm{O}_{3}-\mathrm{H}_{2}$ & $0,9333(2)$ \\
\hline $\mathrm{O}_{2}-\mathrm{O}_{3}$ & $2,5003(2)$ & $\mathrm{O}_{3}-\mathrm{H}_{2}$ & $1,7112(2)$ \\
\hline $\mathrm{O}_{3}-\mathrm{O}_{3}$ & $2,5010, \ldots$ & $\mathrm{O}_{3}-\mathrm{H}_{2}-\mathrm{O}_{3}$ & $161,815(4)$. \\
\hline $\mathrm{P}-\mathrm{O}_{1}$ & $1,5440(1)$ & & \\
\hline $\mathrm{P}-\mathrm{O}_{2}$ & $1,5296(1)$ & & \\
\hline $\mathrm{P}-\mathrm{O}_{\mathrm{s}}$ & $1,5388(2)$ & & \\
\hline
\end{tabular}

Interionic distances

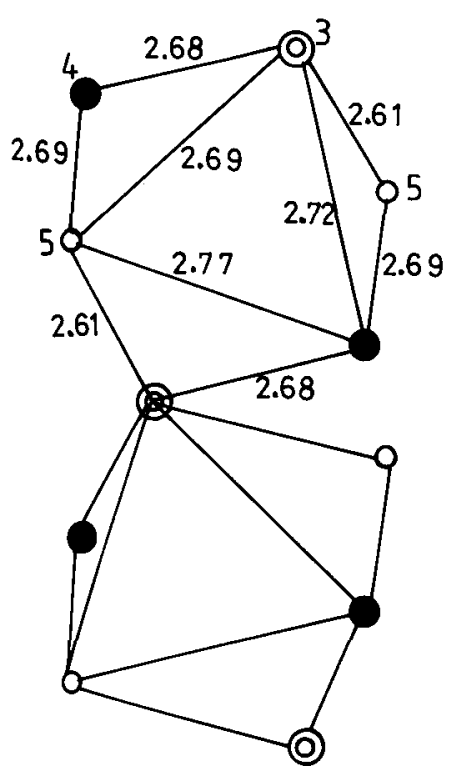

(a)

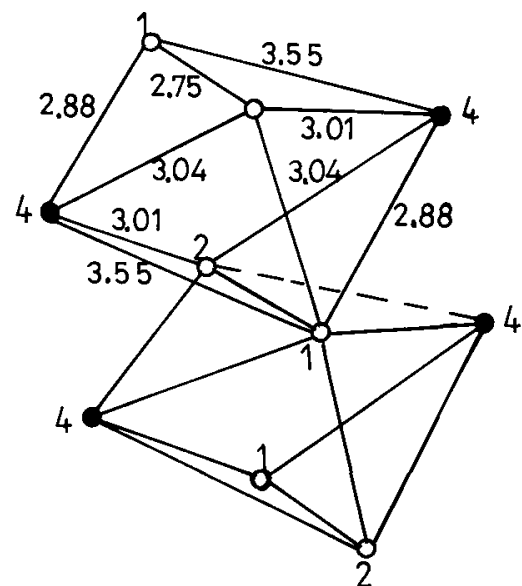

(b)

Fig. 2. (a) Two $\mathrm{Al}_{2} \mathrm{O}_{2}(\mathrm{OH})_{2} \mathrm{H}_{2} \mathrm{O}$ octahedra showing the arrangement of anion. (b) The most distorted $\mathrm{MnO}_{4}(\mathrm{OH})_{2}$ octahedra, with the shared opposite $\mathrm{O}_{1}-\mathrm{O}_{2}$ edges shorter than the others. 
the eosphorite crystals used in this work showed an orange colour, related to the high content of manganese (see Table 1). In fact, the UV-VIS absorption spectrum of our eosphorite (Fig. 3), measured in the $200-750 \mathrm{~nm}$ region at room temperature (RT), consists of bands at 400,417 , 462,526 and $580 \mathrm{~nm}$ (from $350 \mathrm{~nm}$ a dramatical rise in the optical density is observed). These bands are due to $\mathrm{Mn}^{2+}$ and can be related (Table 5) to the ${ }^{6} \mathrm{~S} \rightarrow{ }^{4} \mathrm{G}(\mathrm{Eg}),{ }^{4} \mathrm{G}\left(\mathrm{A}_{1 \mathrm{~g}}\right),{ }^{4} \mathrm{G}\left(\mathrm{T}_{2 \mathrm{~g}}\right),{ }^{4} \mathrm{G}\left(\mathrm{T}_{1 \mathrm{~g}}\right)$ transitions of this ion, in the cubic symmetry approximation (Aguilar and Osendi, 1982; Pappalardo et al., 1983).

Fig. $4 a$ shows the emission spectrum of our natural cosphorite crystal. This spectrum is unequivocally associated to $\mathrm{Cr}^{3+}$ ions (Vergara et al., 1990). It shows two sharp lines, called $\mathrm{R}_{1}$ and $R_{2}$, associated with the two components of the ${ }^{2} \mathrm{E}-{ }^{4} \mathrm{~A}_{2}$ magnetic dipole transition. These two transitions occur as a consequence of a non-cubic crystal field which splits the ${ }^{2} \mathrm{E}$ level. These bands are superimposed on a broad band which spans from 630 to $750 \mathrm{~nm}$. This broad bands, which is lost at low temperatures, is related to the ${ }^{4} \mathrm{~T}_{2} \rightarrow$ ${ }^{4} \mathrm{~A}_{2}$ transition of the $\mathrm{Cr}^{3+}$ ion, (Vergara et al. 1990).
The photoluminescence results show that the typical visible emission spectrum of $\mathrm{Mn}^{2+}$ does not appear. This fact is probably due to the high content of manganese, together with the presence of other impurities (such as Fe) that can act as quenchers of the luminescence of the $\mathrm{Mn}^{2+}$ ion.

The excitation spectrum (Fig. $4 b$ ) confirms that the photoluminescence of natural eosphorite crystals is caused by $\mathrm{Cr}^{3+}$ ions. It consists of two strong and structured bands centred at $431 \mathrm{~nm}$ and $585 \mathrm{~nm}$. These two bands can be related to the ${ }^{4} \mathrm{~A}_{2} \rightarrow{ }^{4} \mathrm{~T}_{1}$ and ${ }^{4} \mathrm{~A}_{2} \rightarrow{ }^{4} \mathrm{~T}_{2}$ spin-allowed transitions (Vergara et al., 1990). It should be pointed out that the resolution of these bands in the absorption spectrum becomes difficult because they are masked by the absorption bands of the $\mathrm{Mn}^{2+}$ ion. However the ${ }^{4} \mathrm{~A}_{2} \rightarrow{ }^{4} \mathrm{~T}_{2}$ (585 $\mathrm{nm})$ band of $\mathrm{Cr}^{3+}$ can still be resolved in the absorption spectrum shown in Fig. 3.

No signal due to $\mathrm{Mn}^{2+}$ was detected in the excitation spectrum of this ion, so that energy transfer from $\mathrm{Mn}^{2+}$ to $\mathrm{Cr}^{3+}$ ions should be disregarded as a possible excitation mechanism. At the same time it should be pointed out that the emission and excitation spectra in Fig. $3 a$ and $b$ are very similar to those reported by Powell et al.

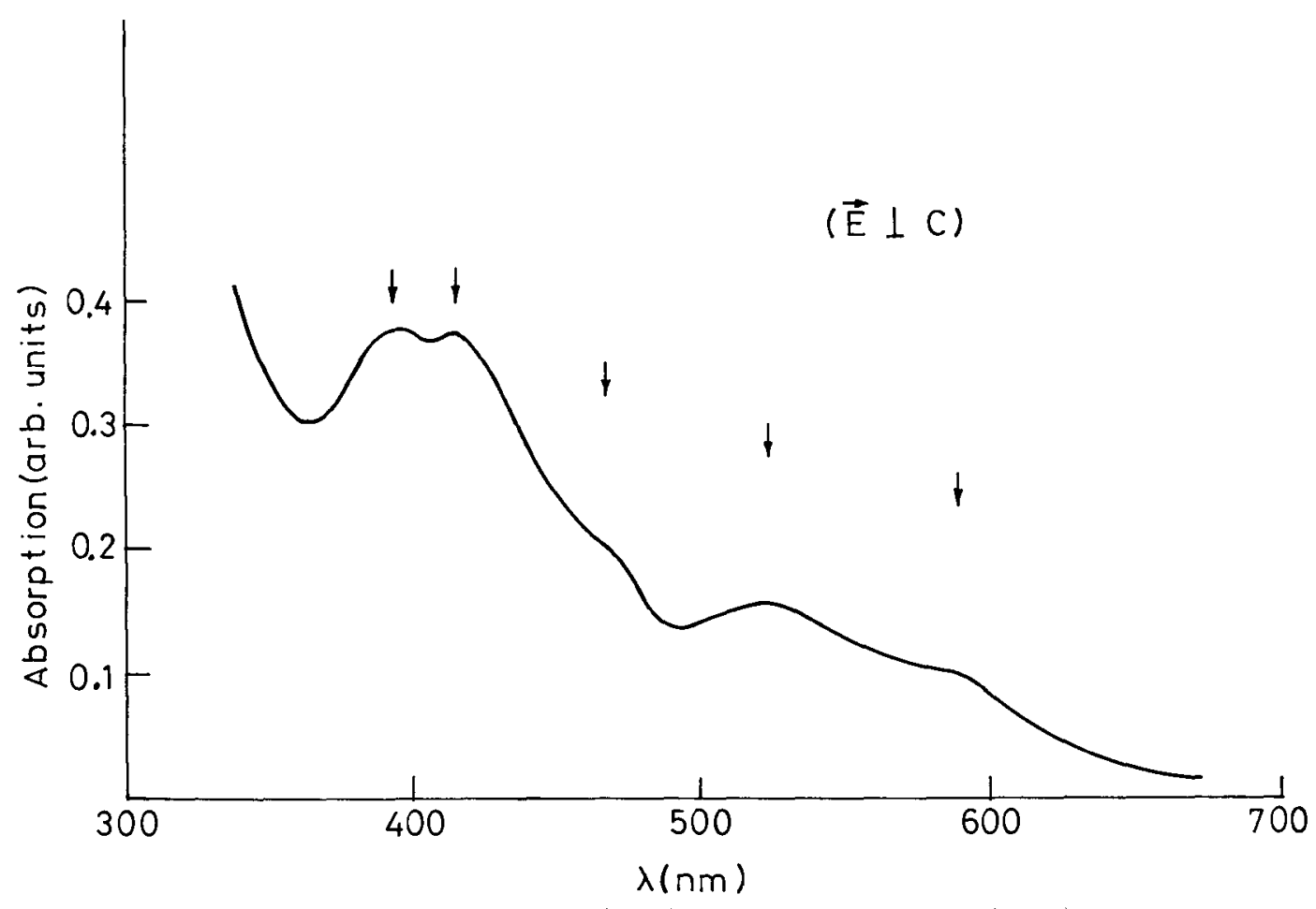

FIG. 3. Absorption spectrum of eosphorite at room temperature $(E \perp c)$. 
Table 5

\begin{tabular}{|c|c|c|c|}
\hline Cubic symmetry & $\begin{array}{l}\mathrm{CO}_{3} \mathrm{Ca}: \mathrm{Mn} \\
\text { Aguilar et al. } \\
(1982)\end{array}$ & $\begin{array}{l}\text { FAP : Sr, Mn } \\
\begin{array}{l}\text { Pappalardo et al. } \\
(1983)\end{array}\end{array}$ & $\begin{array}{l}\text { Eosphorite } \\
\text { this work }\end{array}$ \\
\hline & (a) & (b) & (c) \\
\hline${ }^{6} \mathrm{~s}^{---{ }^{4}{ }^{\mathrm{T}} \mathrm{lg}}$ & 523 & 500 & 526 \\
\hline${ }^{6} \mathrm{~s} \longrightarrow{ }^{4} \mathrm{~T}_{2} \mathrm{~g}$ & 426 & 465 & 462 \\
\hline${ }^{6} s-{ }^{4} A_{1 q}$ & 407 & 415 & 417 \\
\hline${ }^{6} \mathrm{~s}_{\mathrm{S}} \rightarrow{ }^{4} \mathrm{E}_{\mathrm{g}}$ & 401 & 406 & 400 \\
\hline${ }^{6} \mathrm{~s}^{--->}{ }^{4} \mathrm{~T}_{2} \mathrm{~g}$ & 358 & 350 & - \\
\hline
\end{tabular}

$\mathrm{Mn}^{2+}$ ion transition: (a) $\mathrm{Mn}^{2+}-\mathrm{rich}$ carbonate:

(b) Sr, Mn-Flourapatite; (c) Eosphorite. Data in $\mathrm{nm}$.

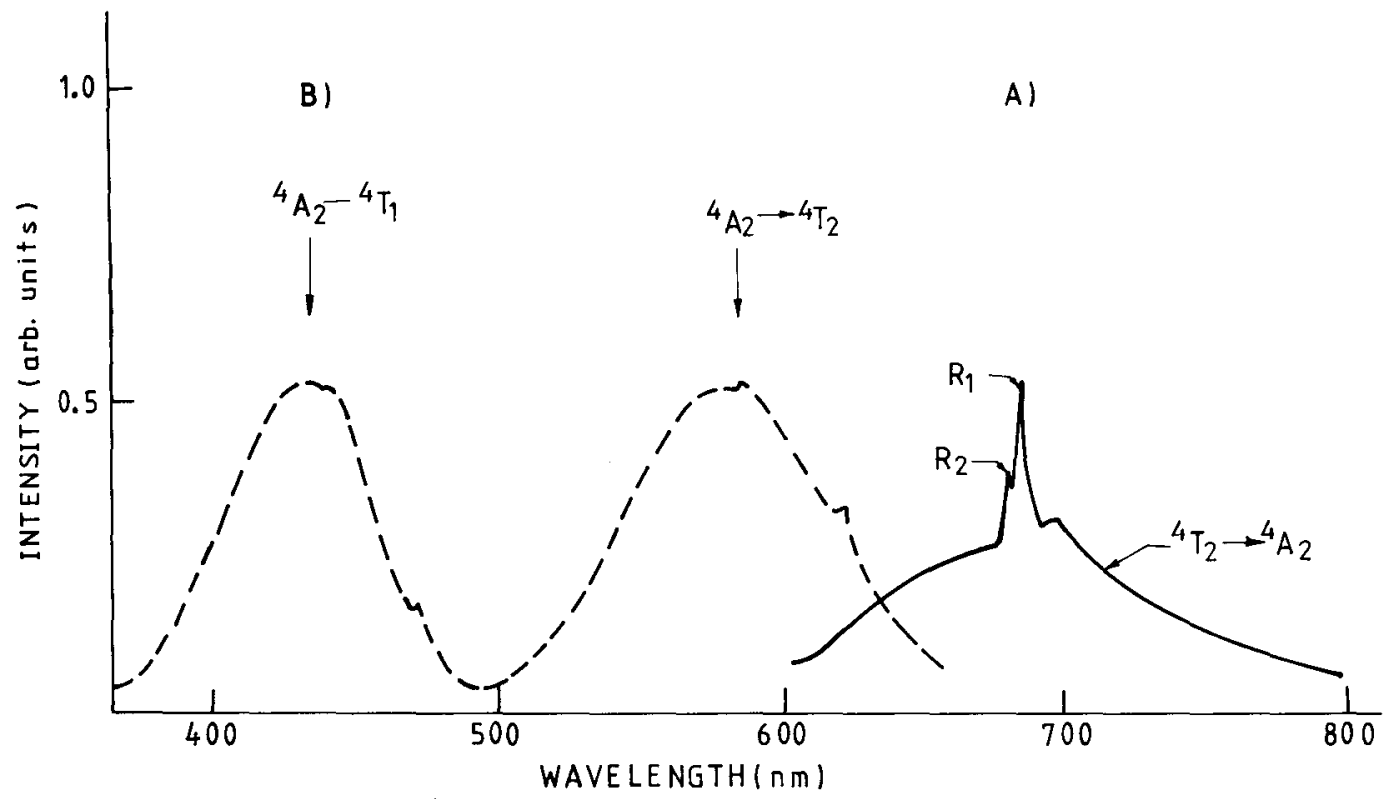

FiG. 4. (a) Emission spectrum of $\mathrm{Cr}^{3+}$ in eosphorite natural crystals at room temperature. (b) Excitation spectrum of $\mathrm{Cr}^{3+}$ in eosphorite at room temperature in the ${ }^{4} \mathrm{~A}_{2} \rightarrow{ }^{4} \mathrm{~T}_{1},{ }^{4} \mathrm{~T}_{2}$ absorption range.

(1985) for the alexandrite $\left(\mathrm{BeAl}_{2} \mathrm{O}_{4}: \mathrm{Cr}^{3+}\right)$ laser crystals. This fact makes this mineral a promising solid-state laser.

\section{Conclusions}

The crystal structure of eosphorite determined by Hanson (1960) has been confirmed but with greatly improved precision, which permitted determination of the hydrogen atom positions and refinement of the anisotropic temperature factors for the other atoms. No evidence of lower symmetry than the orthorhombic space group Cmca has been found.
Photoluminescence results reveal that the fluorescence (emission and excitation) bands are related to the presence of $\mathrm{Cr}^{3+}$ ions.

\section{References}

Aguilar, M. and Osendi, M. I. (1982) Fluorescence of $\mathrm{Mn}^{2+}$ in $\mathrm{CaCO}_{3} J$. Luminescence, 27, 365-77.

Barnes, W. H. (1949) The unit cell and space group of childrenite. Am. Mineral., 34, 12-18.

and Shore, V. C. (1951) The childrenite-eosphorite problem. Ibid., 36, 509-11.

Braithwaite, R. S. W. and Cooper, B. V. (1982) Childrenite in South-West England. Mineral. Mag. 46, 119-26. 
Hanson, A. W. (1960) The Crystal Structure of Eosphorite. Acta Cryst., 13, 384-7.

Hurlbut, C. S. Jr. (1950) Childrenite-eosphorite series. Am. Mineral., 35, 793-805.

International Tables for X-ray Crystallography (1974) Kynoch Press, Birmingham, vol. 4.

King, G. S. D. and Sengier-Roberts, L. (1988) Drugmanite $\mathrm{Pb}_{2}\left(\mathrm{Fe}_{0.78} \mathrm{Al}_{0.22}\right) \mathrm{H}(\mathrm{PO})_{2} \mathrm{OH}_{2}$. Its crystal structure and place in the datolite group. Bull. Mineral., 111, 431-7.

Pappalardo, R. G., Walsh, J., and Hunt, R. B . (1983) Cerium-Actived Halophosphate Phosphors. I. Stromtium Fluorapatites. J. Electrochemical Soc., 130, 2087-96.
Powell, R. C., Lin, Xi, Xu Gang Ouarles, G. J. Walling, J. C. (1985) Spectroscopic properties of alexandrite crystals. Phys. Rev. B., 32, 2788-97.

Stewart, J. M., Kundell, F. A., and Baldwin, J. C. (1976) The X-Ray system; Computer Science Center, University of Maryland, College Park MD.

Vergara, I., Garcia Sole, J., Hoyos, M. A., and Calderon, T. (1990) Fluorescence properties of $\mathrm{Cr}^{3+}$ in natural eosphorite crystals. Solid. St. Comm., 76, 284-92.

[Manuscript received I8 June 1991: revised 8 June 1992] 